\title{
Chapter 4 \\ Security Risk Analysis Perspectives on Central Asia Dynamics
}

\author{
Mihail Păduraru and Claudia-Iohana Voicu
}

\subsection{Security Concepts in Central Asia to the Security Concept}

In the new complex security environment, states are undergoing a paradigm shift, defined by collective security. As an element of action, security is the ability of a system to preserve its functional characteristics under the action of destructive factors which may cause the system to change so that it becomes dangerous to the environment or to the health (including life) of the people who are there in the area of action, causing material, informational, or moral damages. As a cybernetic process, security has its own development, a precise objective (stability), a specific legislation, and an adequate technological support and is based on strategies, norms, methodologies, technologies, processes, actions, and specialized institutions, capable of providing security services, safety, protection, trust, surveillance, but also conditions for the availability and viability of their systems and users.

For a system, security acts both as an amplifier of the positive reaction (to increase the efficiency) and as a limiter of the negative reaction (at the limit of dynamic stability) and the effects of destabilizing factors. Consequently, security is, in fact, the main quality parameter (integrating the elements of reliability, adaptability, and stability) of all processes and systems, without which efficiency is not possible. Pragmatically, the concept of security can be equivalent to the phrase "absence of

\footnotetext{
M. Păduraru · C.-I. Voicu ( $\varangle)$

Chamber of Commerce and Industry Romania-Turkmenistan, Bucharest, Romania

e-mail: iohana.voicu@ccirom-tkm.ro
}

Bucharest Academy of Economic Studies, Bucharest, Romania

M. Păduraru

National Intelligence Academy, Bucharest, Romania

C.-I. Voicu

Military Technical Academy, Bucharest, Romania 
danger," and that of insecurity with the phrase "presence of danger." Therefore, high security corresponds to low danger, and low security corresponds to high danger.

Global strategies, homogeneous or hierarchical, aim to achieve an exhaustive security, either homogeneous on a certain level of security (minimal, sufficient, covering, or secure) or hierarchical on different levels of security for certain components, services, information, or users. The costs of global strategies are high, and their effectiveness depends on the security level established the functional importance of the protected component in the system and the accepted risk levels. But in order to maintain its relevance in the current context, the security concept, seen as a social function, must become more than a tranquility, harmony, and well-being insurer. Security must be seen as the ability of the international community to maintain the balance of power between states so that any individual and society as a whole can benefit from the best state services and maintain a sense of protection.

In addition, one can argue that the active dynamics of the modern-day security environment will revolutionize, reform, and transform at least four areas of social life: community structure, identity dynamics, collective actions, and social order and control. The changes experienced by these four segments converge toward modeling two paradigms specific to the security-based society: a paradigm of networks (marked by changes in the dynamics and social structure, identity, and collective action) and another paradigm of surveillance and monitoring systems (characterized by the new type of social order and control).

In this chapter, we will show that the development of the network paradigm represents the transformation in the social dynamics of communities and in their structure, by multiplying the frames of reference that the individual can use, because nowadays, more than ever, the individual identity loses its monolithic valences, being in a constant construction. Thus, through social mechanisms, the individual, as part of the community, can be influenced, remodeled, and nuanced according to the characteristics of each community. Furthermore, the surveillance and monitor system paradigm is also in a continuous transformation, constantly adapted to the new social challenges in the physical and virtual environment, depending on the security requirements and the needs that society develops in contrast with the spread of new technologies and different types of atypical threats. This way, the globalization processes in the modern world, international cooperation, and demand for continuous transparency have various and variable influences on the general security system of a country. And last, as military capabilities increased globally, to avoid the risk of a new large-scale conflict, state actors have moved away from classical warfare and resorted to a "war waged by other means" and yet, geopolitical rivalries remained unchanged in the quest for a position of influence. Increasing complexity of social, political, economic, and military relations between state and non-state actors demands from policymakers a deep understanding of global and regional dynamics. Therefore, in order to avoid "black swans" (Nassim 2007) and to address the knowledge gaps, researchers have resorted to design new methods of analysis focused on future risks identification and early warning indicators. Thus, the main objective of intelligence analysis researchers is to create a practical instrument for both specialists and policymakers that can decipher the future in relation to atypical threats and their root causes. 


\subsection{Security Threats}

In the following pages, with a simple but effective method, we will briefly illustrate how we built a case study which described the main security challenges in the Central Asia region. The region was chosen due to its challenging nature, fragile stability, and sensitive geographical position. Moreover, since Central Asia is facing a covert multispeed transformation process, the political, economic, and security developments remain uncertain and difficult to predict accurately. We have looked, for example, at how hard and soft power elements are intertwined with climate security in Central Asia. Some threats have chronic roots, inherited from the Soviet past (Ubiria 2015), and others have arisen as a result of the building of new national identities.

At the same time, extensive hydrocarbon reserves and mineral resources have increased the importance of the Central Asia region, while neighboring countries have started battles for gaining access and influence in the area. The Russia-China New Great Game has become a problem of strategic importance in the region since each of the two powers wants to decrease their need for food and energy while securing a low price for their growing imports.

Additionally, Central Asia hosts a network of trade corridors that ensure the flow of commerce between Europe and Asia. So, the stability in the region is mandatory to ensure the operational continuity of global trade and international projects. Planned large-scale infrastructure projects such as the pipeline projects, or the Belt and Road Initiative (BRI) linking regional hubs, and transport corridors are essential for the sustainability of the global economy and efficient resource distribution.

Furthermore, the former Soviet countries underwent a difficult transition in order to design their new national identities after the fall of USSR. The Soviet political and security legacy, economic competition, and border demarcation issues that prevail among the newly formed states were the main reasons for the lack of interest toward cooperation in the region. Moreover, mistrust and lack of dialogue regarding common political and economic issues deepened the cleavages between communities and the countries in region, which are serious threats for long-term stability. Therefore, new challenges arose such as separatism, ethnic tensions, clan territory disputes, insurgency and terrorism, drug and weapons trafficking, and environmental problems (Bichsel 2009). Also, other threats arose from the surrounding geopolitical dynamics, proximity to an ongoing war in Afghanistan, the prevalence of proxy and hybrid warfare, as well as the Arab Spring and color revolutions. All these phenomena led to isolationism as a defense mechanism for all former Soviet republics

\subsection{Risk Analysis}

As illustrated earlier, risk analysis is an interactive process and involves assessing the situation, identifying and evaluating risk factors, determining the risks, and defining 
the mechanisms of reaction and governance of the process. The assessment of security risks and the processes governed by risk consists of: establishing the objectives of the investigation for evaluation, collecting, processing, analysis of the information circumscribed to the objectives and processes, establishing the techniques of investigation and evaluation, elaborating the evaluation report, and formalizing the problems governed by risk (Ilie 2009). Hence, the perception of risk must be oriented toward knowing the reality, understanding the risk factors and consequences, thus becoming directly correlated with the level, the amplitude, or the evolution of the risk. The procedural knowledge, for example, is the social or procedural development and must be oriented toward the disclosure of the causes and correlations, to the evaluation of the impact and the frequencies of production and thus realizing the basis of the forecasts of future events. The harmonization of the differences of thought and concern must be supported by the deepening of the cognitive process, which is the basis of understanding, forecasting, and planning. The acceptance of the reality ought to be oriented toward the analysis of the evolution, and the deduction of causes, as well as the in-depth understanding of the phenomena in order to confront them, exploit them, or govern them.

In other words, risk is assimilated to danger and hazard, but in our context, risk does not only reflect danger or hazard, it can also have a positive connotation. In order to remove this contradiction of perception, it is necessary to approach the concept of risk so that it imposes the obligation to analyze and accept the risk, to treat it, to perceive it, to evaluate it, and to determine it, going beyond the stage of judging the risk as it is considered in everyday life. At the same time, the concept of risk cannot remain in the theoretical sphere, needing to be illustrated by specific situations, by real cases, both representative and particular. The concept of risk must take into account the elements of the apperceptive knowledge, which will guide one toward conclusions, synthesis, and even abstractions, as follows: descriptive knowledgefacts, happenings, and consequences must be oriented toward understanding and explaining (Ilie 2006a).

Concluding on the elements that define the concept of risk, it is necessary to emphasize that knowledge is a complex process, based on conceptuality, methodology, and procedure, with direct, intense, and continuous participation. Equally, knowledge must provide the necessary information and constructions for substantiating decisions that allow significant reduction of uncertainty and the proximity of residual uncertainty, but which can be mastered by rational assumption of risk.

As well, it is important to take into consideration the risk communication process, which implies, such as the existence of the subject, which must be an element of interest for both communicators and those to whom the subject is transmitted; the credibility of the subject, which is part of the motto that truth and trust are the fundamental elements of communication; the will to communicate, which must manifest itself in all situations (for good and for evil), at all levels, and the possibility of anticipating the occurrence of events by eliminating surprise and uncertainty (as much as possible), increasing the rationality and participation in informed knowledge.

According to the standard, risk represents the effect of uncertainty on the situation, with the following meanings which are, firstly, determined by the potential events 
and consequences characterize the risk, $\mathbf{R}$; secondly, by the product between the consequences, $\mathbf{C}$, of an event and its plausibility, p, (possibility, probability, and frequency) determines the level of risk, $\mathbf{R}=\mathbf{p} * \mathbf{C}$; and thirdly, by the Uncertainty represents the lack of information regarding the understanding, causes, consequence, plausibility, and event. Hence, risk refers to potential events, consequences, or their combination and is expressed as a combination of consequences and the plausibility of an event (probability and possibility). The risk, $\mathbf{R}$, represents the probability of an unwanted event occurring, $\mathbf{E}_{\mathbf{n}}, \mathbf{p}$, expressed by the formula $\mathbf{R}=\mathbf{p}\left(\mathbf{E}_{\mathbf{n}}\right)$. Thus, $\mathbf{R}$ represents the product between the probability of the occurrence of an unwanted event, $\mathbf{p}$, and the impact, $\mathbf{I}$, or the consequences, $\mathbf{C}$, of it, which are illustrated by the formulas $\mathbf{R}=\mathbf{p} * \mathbf{C}$ and $\mathbf{R}=\mathbf{p} * \mathbf{I}$, respectively. Also, the risk, $\mathbf{R}$, represents the conjunction between a threat, $\mathbf{A}$, and a vulnerability, $\mathbf{V}$, which makes possible an unwanted event, thus $\mathbf{R}=\mathbf{A} * \mathbf{V}$ (Ilie 2011).

From these definitions and formalizations, the following conclusions can be drawn, for example, the greater the risk, the greater the probability of the occurrence of an unwanted event (with negative consequences), the greater the impact or consequences and the higher the possible threats and vulnerabilities; the risk is lower, as the same elements have lower levels. The attribution for an event of a certain risk (a certain value) is conditioned by two factors: the possibility of the unwanted event occurring and the consequences of its occurrence (Ilie 2013).

Returning to the characterization of the risk identification stage, we emphasize that this implies the perception of the risks and the causes (factors) that produce them and must take into account, such as (1) causality and consequences of risk factors; (2) the time horizons in which they manifest themselves; and (3) the correlations of causes and factors and their cumulative tendencies. The research methodology used to obtain the results presented in this study involved rigorous documentation applied in stages that are specific to the intelligence cycle, as follows: The planning stage, which involves careful planning in order to establish the key intelligence needs (Heuer Jr 2007). The process of gathering information is an essential process of investigation for risk analysis and not an adjacent one, as seen by many analysts. No matter how good an analyst is, one cannot substantiate the hypotheses or determine the results or causal links without the knowledge process on which he relies to ensure an adequate level of credibility, according to the volume, quality, and availability of the information collected for analysis. ${ }^{1}$ For the analysis of information, the two

\footnotetext{
${ }^{1}$ The intelligence gathering stage is supposed to organize a structured system of OSINT sources from which the information was subsequently extracted according to five criteria such as credibility, objectivity, III. accuracy, relevance, and completeness. The collection of information is not a mere gathering of information, but an activity of comparative analysis and research in order to clarify all the investigated aspects. In order to reduce the amount of information, the processing stage involves dropping the collected information through objectivity, accuracy, and relevance. Therefore, the synthesis and analysis stage involves the transformation of the information that was collected and processed in the previous stages into intelligence, through structured analysis methods. In this stage, the aim is to highlight the information that was in full agreement with the objectives of the study. The analysis of information aims to establish the level of credibility, relevance, availability, usefulness, and completeness of the information, as well as the predictive indices for the future evolution of the investigated process in order to anticipate a risk.
} 
most commonly used analysis techniques are known: aggregate analysis and case analysis. This aggregate analysis characterizes the veracity and correlation of the information collected through statistical-mathematical techniques, as well as the correlations between different characteristics, a systematic representation, and the possibility of aggregation according to different criteria in order to elaborate the (strategic) synthesis information. The aggregation function must be sensitive (the variations of the function are determined by the variations of the arguments) and noncompensatory (the variations of the variables are not compensated), and the stage of drafting the intelligence product, followed by its dissemination to the OSCE, involves the transformation by coherent aggregation of the intelligence obtained through analysis, into knowledge. Thus, the final intelligence report is obtained and then displayed in a legible, coherent, and comprehensive format. During the research, the following predetermined objectives were taken into account, namely first, the selection of relevant data and information so that a solid study can be carried out, both methodologically and through the quality of the documentary value. Secondly, the defining a reference framework in accordance with OSCE standards, which will allow future research in order to anticipate unforeseen events that could adversely affect the dynamics of the Central Asian region's development. We used a number of exactly 100 risk factors and indicators that can influence the future security dynamics in the Central Asia region have been identified. They are divided into different sets of factors and indicators, sub-categorized into the following categories: political, security, economic, social, military, and environment. Both the factors and the risk indicators were compared to obtain the two most relevant ones, which can be used to create a 2/2 matrix in order to develop a number of four possible scenarios in a future research. Subsequently, a regional security index was created by assigning weights and measurement scales to each indicator for each country in the region separately. Due to the detailed break-down of identified relevant factors which determine the current security climate of the studied region, the index is an accurate tool to identify vulnerabilities and to measure the overall threat level. As the end results emphasize the elements which have a significant impact in the region, the results can be used in future in-depth studies.

For each stage of the research methodology, clear and coherent criteria have been established to highlight the objectives pursued. The criteria were introduced in some calculation matrices and scientifically measured to determine comparable results. By this method, mathematical (quantifiable) values could be attributed to subjective intelligence data, thus the result being an objective study, both quantitative and qualitative.

\subsection{The Risk Factors}

The main vulnerability identified was "social cohesion," and it represents the factor with the highest risk weight in our analysis that can influence the future political dynamics of the region. To provide context, to guarantee stability and predictability, 
Central Asian states need to have a clear mechanism set in place to ensure a smooth transfer of power in case of a sudden power vacuum. However, as all the five nationstates are still young, state-building and nation-building processes are still under development. With the exception of Kyrgyzstan, all the other four regional state leaders have chosen to name successors in order to maintain stability and continuation of their political legacy.

Also, there is a widespread belief that the assimilation of western democratic values and organizing of open elections could bring chaos and weaken the current political elites by stimulating opposition. Moreover, regional leaders are threatened by internal forces and potential opposing coalitions and thus focus on regime survival above all else. As such, regional leaders have adopted a clientelist and authoritarian approach, strengthening their intelligence organizations and police forces. As a result of this, "internal police forces have been enjoying greater state resources than regular armies in all Central Asian states" (Blank 2012).

The second issue identified was "authoritarianism," a threat to global market access which can be defined by local trade barriers, corruption, excessive bureaucracy, and a lack of a proper physical and regulatory infrastructure due to limited regional cooperation. In other words, economic development in Central Asia is hampered by insufficient real economic cooperation and states' unwillingness to implement mutually beneficial strategies to common issues in areas such as energy, water, and agriculture. Namely, local regimes' chronic mistrust and preference for zero sum games prevents reaching an agreement on long-term issues such as creating new energy and water supply management systems to address the water-energy exchange mechanism nexus inherited from Soviet times. Another point of urgency of a common agenda instead of national self-sufficiency attempts is the impending water crisis in Uzbekistan, Kazakhstan, and Turkmenistan, which could lead to an agricultural blockage and potentially destabilize the entire region.

Likewise, research showed causality between capital flight and low FDIs, corruption, institutional weakness, and rule of law deficiencies. To emphasize, the absence of dialogue and conflict resolution mechanisms, in addition to local corruption, foreign capital restrictions, and overregulation, creates an unattractive investment environment as they raise the cost of doing business. The perception is enforced by a weak rule of law as an element of uncertainty, as countries lack agreement enforcement guaranties and investors lose confidence in their contracts being honored or resource availability in case of disaccord.

Another key point is that due to geographical positioning, resource distribution, and infrastructure, it is impossible for any Central Asian country to develop a sustainable economy without engaging in regional cooperation (Paun 1997). That is to say that an economically sustainable system must have the capability to ensure countries' growing goods and services demands while maintaining manageable levels of public debt, without creating extreme sectoral imbalances. With this in mind, the analysis of the political and economic index segments revealed a strong link between government policies and potential external support or loss of support.

Under the circumstances, it is clear why, while building their identity as new states, Central Asian countries mostly balanced the fragile geopolitical environment 
by preferring bilateral agreements to multilateralism. Moreover, due to its position, the region has long been seen as a strategic chessboard for great power expansion, nowadays having to navigate foreign economic relations and diverging interests of actors such as China, Russia, the USA, the EU, Iran, India, and Pakistan. Significant in this case is the before-mentioned Russian-Chinese New Great Game in the region, which uses investment and export infrastructure dependency as leverage. Russia is the traditional transit route for bringing European goods and services to Central Asian markets, while also providing the infrastructure for regional countries to export their goods to Europe.

\subsection{Case Study: Ukraine and Its Push Factor to Central Asia and Russia}

The Ukraine conflict has exposed nations' vulnerability for their local economies, as logistical complications have made trade dependent on the geopolitical status quo. In addition, the crisis also became a direct threat for the business environment in Kazakhstan's case, due to the country's strong economic relations with Ukraine, while also marginally affecting small- and medium-sized enterprises in the rest of the region.

Simultaneously, these evolutions show that the international community's concerns regarding the economic sanctions imposed on Russia, and Russia-West mutual commodity trade slowdowns were not far off. International sanctions meant Russia's economic stagnation, labor market reduction, and ruble devaluation, while also lowering global hydrocarbon market prices (one of Central Asia's main source of revenue). Though all of Central Asia faced economic uncertainty due to strong ties to the Russian economy, the most affected was Kazakhstan, a founding member of the EAEU.

The economic circumstances reduced investments from Russia to the region, as well as labor migrant remittances. Another key point is that the Ukrainian crisis' ripple effects included the souring of the Customs Union activity, directly affecting Central Asia's economic security. The reason for this is Kazakhstan and Belarus' refusal to support Russian sanctions on EU, US, and allied imports. To add on this, as Central Asians began to feel the economic consequences of the trade war between the West and Russia, regimes began to question the economic dependency on the Russian economy and seek alternatives without damaging their ties to Moscow. Partnership with Russia based on Eurasian integration is not the only option for Central Asian states. Alternative economic projects should not be viewed with distrust or as a political aggression toward Russia.

To have a clearer picture which supports the understanding of the geopolitical complexity of the Central Asian area, one should analyze the Ukraine case. Furthermore, the conflict in Ukraine generated multiple events which changed the geopolitical configuration of Eurasia. In 2014, a disagreement between Russia and Ukraine regarding 
the use of the Russian strategic military base from Black Sea set the premises for the invasion of the Crimea peninsula by Russian forces. The conflict later expanded to Donbas and Lughansk and led Ukraine into an internal war.

Moreover, the new geopolitical hotspot in Eastern Europe became the target of a mix of hybrid tactics matched by classical military actions, designed to legitimize Russia's presence and destabilize the country from within. Thus, the weaponization of ethnic tensions, social discontent, and the spread of propaganda and disinformation can expose the vulnerabilities of multiethnic societies where multiple identities coexist in the ideological field of a single state. This social engineering set of tactics is effective due to the Ukrainian government's failure to cultivate a unitary national sentiment, and the lack of a consistent domestic policy to address minorities' alignment with a common set of values.

Correspondingly, the evolution of Eastern Ukraine served as an example for Central Asian states, which also have significant ethnic Russian minorities, showcasing the need to implement a strong domestic policy to discourage potential dissidence. As such, all states tightened government control of interethnic relations, religious practices, and language policies. It is noteworthy to mention the proactivity of Kazakhstan, which also hosts the largest Russian community and chose to actively develop an interethnic accord. To compare, in response to religious tensions and the growth of an Islamic party, the Islamic Renaissance Party of Tajikistan (IRPT), Tajikistan, chose to adopt a set of repressive measures that severely restricts the Muslim community and scrutinizes any religious gathering or association.

Also, since the operations in Crimea and, later on in Donetsk, proved that artificially joining "divided people" and targeting social fissures can create large ruptures in states' stability, it is likely that the scenarios will be repeated. Consequently, Central Asian regimes are trying to prevent the intensification of ethnic or confessional public movements, which could instigate wider revolts and threaten their legitimacy. Furthermore, the Ukrainian crisis showcased an additional challenge in social changes - the growth of militaristic sentiments in certain population groups due to discontent over government policies and a slow rate of development, all of which are fueled by the information background pushed in the media landscape.

In Central Asia's case, it is likely that the employment of similar tactics to destabilize current leadership could try to grow the Islamic solidarity-based identity and target Muslim groups (Jonson 2006), particularly in areas like the Ferghana Valley. Going forward with this scenario, a military intervention into the region would stimulate a rise in popular support of extremist organizations and the potential resurgence of an Islamic State, especially as all Central Asian countries are dealing with the return of foreign fighters since the fall of Daesh.

Moreover, the emergence of information warfare tested in Ukraine exposed a new set of vulnerabilities of the five regional states as their security systems are still highly interlinked with Russian technological and training assistance. Similarly, the weakness regarding information-flow control is also applicable to the entire public sector. The region's countries do not have a strong, authentic, and locally created information area. They still maintain a dependency on foreign media, particularly 
of Russian origin. Consequently, local perception of political and economic realities is skewed by the perspective of external actors with their own foreign policy preferences.

In addition, the regional security index shows a higher level of instability risk for countries with a higher percentage of Russian-speaking minorities, as their discontent could be used as justification for military Russian intervention, as per the Ukrainian precedent. Moreover, local leaders' delays in simplifying Russian citizenship procedures for USSR-born individuals or their descendants are an acknowledgment of this risk. This potential threat is particularly relevant as Russian media outlets periodically demand legitimation of territorial claims against Kazakhstan and a number of other Central Asian territories. Also, during the height of the Ukrainian crisis, Russia systemized the management of labor migrants from Central Asia and the interaction with their most influential leaders. Additionally, a bill introduced for debate in the Federal Duma proposed an enhancement of the powers of ethnic and cultural autonomous communities by converting them into not-for-profit entities. This would entail the possibility of direct financing and turning them into vehicles for influence.

Further fueling Central Asia's mistrust and suspicion, the changes of Russia's borders after the addition of Crimea, as well as previous military involvement in regions with strong separatist sentiments such as the Pridnestrovian Moldavian Republic, Abkhazia, and Ossetia sent a wave of insecurity through the entire former Soviet space. States changed their perception of the strength of their own borders against potential foreign military operations, especially as Central Asia is dealing with border demarcation issues, uncontrolled enclaves, and a diverse ethnic environment dominated by clans with dormant territorial claims (Collins 2006).

More uncertainty was added by Russia's accelerated strengthening of its military presence in the region, by setting up new military bases in Tajikistan and Kyrgyzstan and upping its military contingent in both countries. By the same token, the security indicators analyzed show increased militarization and an emphasis on policy of force among all the five countries. Similar significant threats include the lack of an independent cybersecurity infrastructure in every country, which could prevent the use of Internet resources by extremist groups to recruit people and conduct illicit trade, as well as potential disseminate unauthorized state secrets.

Additionally, collaborations with foreign entities which possess valuable knowhow and could help advance the local economy is made difficult by excessive bureaucracy and state controls. This is a due to the fact that, to prevent potential replication of "color revolutions" in the region, which in Ukraine have led not only to a change of the political regime, but also to a civil war, Central Asian government authorities have been enhancing supervision of the tertiary sector-NGOs, Internet media, social networks, and foreign grant programs. 


\subsection{The Role of China in Risk Analysis}

China has strengthened its position in the region and maintains its neutral status without engaging in any conflict overtly. China is the only strong global economic partner that has stepped up the implementation of major economic projects in Central Asia. Furthermore, the Silk Road Economic Belt project and its implementation are in synergy with the Eurasian integration processes. China is becoming an increasingly important investor and lender to the countries of the region. Beijing is trying to expand its road and rail infrastructure to export various Chinese goods not only to Central Asia, but also to Europe. The alternative to Russia's infrastructure with the most potential is China's BRI, which transits Central Asia, creating a direct trade corridor toward European markets.

Russia's actions in Ukraine have led Beijing to diversify its methods and make more efforts to intensify its influence operations in both Central Asia and the AsiaPacific region. It is expected that China will also grow its mechanisms for economic cooperation in Central Asia, especially taking into account China's increasing energy demand and Central Asia's need to diversify its export markets. China is the largest importer of energy resources from Kazakhstan and Turkmenistan. At the same time is the main economic partner for most countries of the Central Asia region. China filled the void left by the Russian economy's contraction and is currently building its economic presence in "Greater Central Asia," taking on large-scale infrastructure projects and investments. Thus, it is likely that it will deepen cooperation with regional regimes such as Turkmenistan, which need support to finance TAPI and export gas and oil to Afghanistan, Pakistan, and India (Kalyuzhnova 2008).

For local regimes, a new challenge will be to navigate between China's expansion of military interest in the region without losing the support of its traditional allyRussia. An example in this case is China's creation of the Quadrilateral Cooperation and Coordination Mechanism (QCCM), which includes Tajikistan, Pakistan, and Afghanistan, on top of the existing SCO and CSTO security cooperation frameworks (Korzun 2018).

To address these risks and ensure their countries' proper autonomous development and interests, Central Asian leaders would have to develop a political and economic hedging strategy between Russian and Chinese interests (Jackson 2014). As the lines are blurring between economic and political agendas, regional leaders' weariness of potential effects of foreign influence on their countries' security is not unfounded (Geeraerts and Salan 2016).

\subsection{Key Findings and Conclusion}

Based on above-mentioned methods and case studies, a regional security ranking of the states was created, taking into account their overall score. The first position, of the most secure and stable state, was occupied by Kazakhstan, followed by Uzbekistan, 
Turkmenistan, Kyrgyzstan, and Tajikistan. Moreover, even though traditional rankings such as Global Firepower 2019 Military Strength Ranking (Global Firepower 2019) place Uzbekistan higher than Kazakhstan in terms of pure military strength, when also taking into account elements relating to troops' military sentiment, such as discontent over benefits, corruption, technology used, and other adjacent factors, the security index places Kazakhstan in first place.

Additionally, research showed discontent in all the five member states over the slow integration of new technology in the public sector infrastructure. Though Kazakhstan and Uzbekistan have taken several steps to adapt to the digital economy, including developing their own cybersecurity systems, technical and administrative assistance from other countries or international organizations is needed to build the whole infrastructure (Omelicheva 2015).

In terms of business-friendly policies and economic competitiveness, Kazakhstan was the highest ranked among the states, while Tajikistan the last. Likewise, the same result arose from comparing quality of life. Also, regarding personal freedoms, while Turkmenistan ranked worst overall for religious freedom due to the severity of the repressive measures taken against religious minorities, the lowest score was received by Tajikistan.

The "three evil forces, radicalism, extremism, and terrorism" (Doyon 2019) exploit the problems already existing in society and economy in order to spread dissatisfaction and incite ethnic conflicts. Countermeasures should target the use of the Internet for terrorist and extremist purposes along with monitoring citizens of SCO states who have been involved in fighting activities in Syria, Iraq, or other states.

The fact that a large number of the population of Central Asian countries live in poverty can lead to a sense of marginalization, and, under the umbrella of this, individuals could seek refuge in religion. This vulnerability could be exploited by certain terrorist-extremist groups. Ignorance and lack of access to a decent education, in conjunction with the fear of publicly debating the issue of extremism and terrorism, may be a fertile ground for the development of extremism and radicalism in the region (Navrotskyy 2013).

However, in the recent years, Central Asian governments have stepped up their policies in the fight against terrorism and adopted preventive measures that have kept away terrorist attacks. The same measures must be taken to combat ethnic separatism. Transnational relations have negative connotations in the Central Asian region, such as cross-border organized crime, drug trafficking, ethnic and religious extremism. Moreover, these threats reflect the need for transnational cooperation and collective mobilization with the potential to eliminate cultural and social stereotypes that come as historical baggage (Cooley 2012). Increased transnationalism should not be seen as an alternative to national identities that are indispensable for regional cooperation and integration.

Weak democratic institutions and restrictions on society have made the countries of the Central Asia region unattractive as economic partners at interstate or corporate level (Omelicheva 2015). Neither investors nor businessmen trust that the contracts will be honored or that they will be treated fair by the authorities in the event of a 
dispute or unforeseen situation. In the last years, due to corruption, weak legislation, and the prevalence of organized crime, the cost of business activities increases exponentially, creating economic uncertainty (Canfield and Paleczek 2011).

To sum up, the following aspects should be emphasized that first, it is essential to direct attention from internal threats to international cooperation with western partners in order to identify solutions for common problems. Secondly, it is imperative to initiate and develop a set of institutional partnerships aimed to address the foreign fighters' issue. Thirdly, it is important to organize working groups or videoconferences between officials from specialized western institutions and decision-makers and analysts from Central Asian countries, on issues related to extremism, ethnic separatism as well as other topics in the area of atypical threats, and last, in the field of counter-terrorism, it is necessary to transfer knowledge from the tactical to the strategic level regarding capacity building with respect for international laws and human rights, regarding understanding motivations, monitoring activities, cooperation between intelligence agencies and prohibition of certain rights for specific individuals.

When we look at Central Asia, one should take into consideration that the overall level of security and stability can erode quickly into a major conflict in the area due to its strategic position as a buffer between large powers. If one considers that the security forces of the Central Asian states are accustomed to an obedient population, one that is controlled and which dares not oppose the regime, the following questions are raised, primarily how would security forces from Central Asian states react to a confrontation with a well-defined, trained, and armed group, focused on causing chaos? It is also unclear, what support could the governments of Central Asian states expect from their citizens? If attacked, or faced with domestic challenges, to whom will Ashgabat, a neutral country with no clear defense agreements, ask for immediate help? If militants of an extremist or terrorist organizations intensified their activities in Central Asia, what would be the reaction of neighbors such as Russia, China, or Iran?

Traditional security concerns such as interstate rivalries and the security dilemma resulting from them can be applied in the context of Central Asia. Since the region can be considered an unstructured regional formation or a multilayered security complex, this gives rise to security challenges associated with the lack of coordination between countries (Haas 2016).

Also, the main security threats and risks in the Central Asian countries have internal roots and are direct consequence of weak governance policies. As in other fragile states, these challenges refer to identity issues. The absence of national cohesion and the weak institutions of the Central Asian countries represent strong internal risks to the governance regimes. These vulnerabilities generate responses of "regime stability policy" from the government. Under those policies, the short-term survival strategies of the regime replace long-term state-building policies.

At the international level, the security challenges in Central Asia are determined by the peripheral character of the Central Asia region in the global context. Considering the absence of an effective regional structure as a recognized security provider, this determines the presence of extra-regional actors of public and private nature 
in the region. As a rule, this presence is associated with the desire to gain access to natural resources or with the desire to implement geopolitical projects that may bring new and very important security risks in the region. In addition, Central Asian states assume their satellite status quo and gravitate around different regional powers in the immediate vicinity. Thus, there is a risk of special importance, namely the fragmentation of the regional unit that can cause a transformation of the entire regional structure.

Finally, one of the most important security risks for the Central Asian countries is the ability of certain regional and international powers to influence and alter the perceptions of international law. This is caused by Central Asia's lack of its own internal and regional structures to provide complete security and tackle emerging challenges quickly. Therefore, the ongoing transformation and modernization process of the entire region could be the biggest security risk for the coming years.

\section{References}

Blank, S. (2012). Whither the new great game in Central Asia. Journal of Eurasian Studies, (3), $147-160$.

Bichsel, C. (2009). Conflict transformation in Central Asia: Irrigation disputes in the Ferghana Valley. US: Routledge.

Canfield, E. R. L., \& Paleczek, G. R. (2011). Ethnicity, authority, and power in central Asia: New games great and small. Routledge, US: Central Asian Studies Series.

Collins, K. (2006). Clan politics and regime transition in Central Asia. UK: Cambridge University Press.

Cooley, A. (2012). Great games, local rules: The new great power contest in Central Asia. UK: Oxford University Press.

Doyon, J. (2019). Counter-extremism' in Xinjiang: Understanding China's community-focused counter-terrorism tactics. War on the Rocks.

Geeraerts, G., \& Salman, M. (2016). Measuring strategic hedging capability of second-tier states under unipolarity. Chinese Political Science Review, 1(1), 62.

Global Firepower. (2019). Military strength rankings.

Haas, M. (2016). Security policy and developments in Central Asia: Security documents compared with security challenges. Journal of Slavic Military Studies (Taylor \& Francis).

Heuer, R. J., Jr. (2007). Psychology of intelligence analysis (2nd ed). USA: Pherson Associates LLC.

Ilie, G. (2006a). Security of the business environment. Bucharest: UTI Press Publishing House.

Ilie, G. (2006b). The systemics of variables aggregated for security, communication and protection. Detective Publishing House.

Ilie, G. (2009). From management to governing through risk. Bucharest: UTI Press Publishing House.

Ilie, G. (2011). Risk: Measuring uncertainty. Bucharest: UTI Publishing House.

Ilie, G. (2013). The structure of risk-concepts, standards, opinions. Buchares: UTI Publishing House.

Jackson, V. (2014). The rise and persistence of strategic hedging across Asia: A system-level analysis. In Strategic Asia 2014-2015, US alliances and partnerships at the center of global power. The National Bureau of Asian Research.

Jonson, L. (2006). Tajikistan in the new Central Asia: Geopolitics, great powers, rivalry and radical islam. UK: IB Tauris \& CO Ltd. 
Kalyuzhnova, Y. (2008). Economics of the Caspian Oil and Gas Wealth: Companies, governments, policies. US: Palgrave Macmillan.

Korzun O. (2018). China joins Afghanistan, Pakistan, Tajikistan in security Aaliance. Strategic culture foundation.

Nassim, N. T. (2007). The black swan: The impact of the highly improbable. US: Random House Inc.

Navrotskyy, V. (2013). The east-west strategic corridor from Central Asia to Europe and Ukraine's interests. CPCEW Bucharest, 6(10).

Omelicheva, M. (2015). Democracy in Central Asia: Competing perspectives and alternative strategies. USA: University Press of Kentucky.

Paun, M. (1997). Analysis of economic systems. Bucharest: All Educational SA Publishing House.

Ubiria, G. (2015). Soviet nation building in Central Asia: The making of the Kazakh and Uzbek Nations. London, UK: Routledge.

Open Access This chapter is licensed under the terms of the Creative Commons Attribution 4.0 International License (http://creativecommons.org/licenses/by/4.0/), which permits use, sharing, adaptation, distribution and reproduction in any medium or format, as long as you give appropriate credit to the original author(s) and the source, provide a link to the Creative Commons license and indicate if changes were made.

The images or other third party material in this chapter are included in the chapter's Creative Commons license, unless indicated otherwise in a credit line to the material. If material is not included in the chapter's Creative Commons license and your intended use is not permitted by statutory regulation or exceeds the permitted use, you will need to obtain permission directly from the copyright holder. 